\title{
Maintenance for Repaired RC Column Exposed to Chloride Attack Based on Probability Distribution of Service Life
}

\author{
Sang-Hwa Jung ${ }^{1)}$, Hyun-Min Yang ${ }^{2)}$, Keun-Hyeok Yang ${ }^{3)}$, and Seung-Jun Kwon ${ }^{4), *}{ }_{(\mathbb{C}}$
}

(Received September 29, 2017, Accepted February 6, 2018)

\begin{abstract}
Chloride attack is one of the most critical deterioration due to rapid corrosion initiation and propagation which can cause structural safety problem. Extended service life through repairing is very important for determination of maintenance strategy. Conventionally adopted models for estimation of life cycle cost have shown step-shaped elevation of cost, however the extension of service life is much affected by quality of construction and repairing materials, which means engineering uncertainties in residual service life. In the paper, reinforced concrete column with three different mix proportions exposed to chloride attack are considered, and repairing numbers with related costs are evaluated through probabilistic technique for maintenance. With a given exposure condition, service lives with normal probabilistic distribution are considered, and the effect of design parameters such as coefficient of variation of service life and 1st repairing timing are investigated. The comparison of results from conventional approach (step-function) and probabilistic approach are performed. When calculating repair frequency for intended service life through probabilistic model, the required repair frequency is evaluated to be 6.71 times for OPC, 4.09 times for SG30, and 2.95 times for SG50, respectively. The probabilistic model for repairing cost is evaluated to be effective for reducing the repair frequency reasonably with changing the intended service life and design parameters.
\end{abstract}

Keywords: chloride attack, maintenance, probabilistic technique, service life, repairing frequency.

\section{Introduction}

With increasing significance of longevity of infrastructure, maintenance strategy against deteriorating agent has been issued. Reinforced concrete (RC) structures subjected to chloride attack are always exposed to steel corrosion inside concrete (Broomfield 1997; Song et al. 2006). The problems initiated from esthetic degradation like rust stains usually propagate to serviceability degradation such as cracking and excessive deflection, and worsened to safety problem with spalling of cover concrete and reduced bearing capacity (Broomfield 1997; Song et al. 2006; Alonso et al. 2002; AlAmoudi et al. 2009). For the reasons, many researches have been focused on durability design and quantitative deterioration evaluation, and have suggested a durability design code and the related guidelines for chloride attack (European

\footnotetext{
${ }^{1)}$ Korea Conformity Laboratories,

Gasandong, Seoul 08503, South Korea.

${ }^{2)}$ Department of Architectural Engineering, Hanyang University, 55, Ansan 15588, South Korea.

${ }^{3)}$ Department of Plant and Architectural Engineering, Kyonggi University, Suwon 16227, South Korea.

${ }^{4)}$ Department of Civil and Environmental Engineering, Hannam University, Daejeon 34430, South Korea. *Corresponding Author; E-mail: jjuni98@hannam.ac.kr Copyright (c) The Author(s) 2018. This article is an open access publication
}

Committee for Standardization (Comité Européen de Normalisation, CEN) 2000; Japan Society of Civil Engineering, JSCE 2007; American Concrete Institute, ACI 2011).

Recently, life cycle cost analysis (LCCA) techniques which cover the cost estimation from design to dismantle stage has been developed, which induces technically supported and cost-benefit construction and maintenance. The LCCA techniques are based on the summation of the cost in each stage. Recently several techniques based on probability manner are applied, however they are focused on cost element evaluation so that deteriorating phenomena which directly affect services life or maintenance level are not considered in quantitative manner. In the previous researches, probabilistic approaches are applied to LCC evaluation with statistics and distributions regarding cost at each stage (Martinez 2001; Mulubrhan et al. 2014). Cost estimation through probability analysis has been performed assuming degradation of asphalt and concrete for 100 years but it only provides repairing cost estimation not based on the quantitative modeling but on the assumed simulation (Salem et al. 2003; Swei et al. 2013; Chan et al. 2008). In the previous models, the probability techniques mainly dealt with the cost connections like investment, running, maintenance, fault, and dismantle without deterioration evaluation/prediction based on probability approach (Nasir et al. 2015; Bian et al. 2014). Many complicated numerical techniques such as artificial neural network (Nasir et al. 2015; Bian et al. 2014), fuzzy logic systems, and adaptive network-based fuzzy inference system are implemented for LCCA but repairing 
cost is usually determined through not probability method but deterministic method (Flintsch and Chen 2004; Barringer and Weber 1997; Rahman and Vanier 2004).

The repairing timing and the related extension of service life are changed with variation of durability design parameter like cover depth and quality of concrete. For estimation of repairing number and cost in the view of engineering, a quantitative governing equation containing design parameters, mix conditions, and exterior conditions should be determined in advance. Critical condition which means maximum allowable criteria is compared with the required minimum performance considering service life (Kwon 2017). In the conventional LCC program for chloride attack, the induced chloride content from surface chlorides is evaluated and repairing cost is calculated after determining the period when the induced one exceeds the critical chloride content which can cause corrosion initiation (Thomas and Bamforth 1999; Thomas and Bentz 2002). This technique is a representative deterministic manner and repairing cost is simply repeated considering the same service life of the structure with increasing interest rate.

In the work, probability technique is applied to repairing cost estimation considering the variations of initial service life and extended service through repair. The actual RC structures (column) with three different mix proportions are assumed under chloride attack. The repairing frequency is evaluated considering the conditions of initial and repaired conditions with constant repairing cost. In the deterministic method, the repairing cost increases repeatedly with stepshape but continuously increasing cost is evaluated in the probabilistic method, which can provide reasonable cost estimation and reduction of repairing number through simple reconsideration of intended service life and design parameters.

\section{Theory of Repairing Cost Estimation with Probabilistic Approach}

\subsection{Case of Maintenance-Free Period over Initial Service Life (TOTAL-LCC 2010)}

The algorithm for repairing cost estimation is adopted from the previous research (TOTAL-LCC 2010) where the probability distributions for initial and the extended for service life through repairing are assumed as normal distributions. When maintenance-free period in the initial construction is longer than intended service life, repairing number equals to 0.0 . This condition can be formulated as Eq. (1) with 1 st repairing time $\left(T_{1}\right)$ and intended service life $\left(T_{\text {end }}\right)$.

$$
T_{1} \geq T_{\text {end }}
$$

Defining the mean of $1 \mathrm{st}$ repairing time as $\overline{T_{1}}$, normalization parameter $(\beta)$ for 1 st repairing can be written as Eq. (2).

$$
\beta_{1}=\frac{\left(T_{\text {end }}-\overline{T_{1}}\right)}{\sigma_{1}}
$$

where $\sigma_{1}$ is standard deviation of $T_{1}$ based on normal distribution.

The probability for the case of no repairing $\left(\mathrm{P}_{1}\right)$ can be calculated through Eq. (3) for the 1st repairing timing.

$$
P_{1}=\int_{\beta_{1}}^{\infty} \frac{1}{\sqrt{2 \pi}} \exp \left(-\frac{\beta^{2}}{2}\right) d \beta
$$

\subsection{Case of Multiple Repairing (Maintenance-} Free Under Initial Service Life) (TOTAL-LCC 2010)

The 1 st repairing time comes when $T_{1}$ approaches to $T_{\text {end }}$, and the summation of $T_{1}$ and $T_{2}$ (2nd repairing time) is greater than $T_{\text {end }}$. The condition can be shown in Fig. 1. The normalization parameter (safety index) for the condition is written as Eq. (4).

$$
\beta=\frac{\left(t_{2}-\left(\overline{T_{1}}+\overline{T_{2}}\right)\right)}{\sqrt{\sigma_{1}^{2}+\sigma_{2}^{2}}}
$$

where $\overline{T_{i}}$ and $\sigma_{i}$ are mean and standard deviation of $i$ th repairing time with increasing $t_{2}\left(=\mathrm{T}_{1}+\mathrm{T}_{2}\right)$.

For calculation of total probability area in Fig. $1, \mathrm{P}_{2}^{*}$ should be defined in advance through Eq. (5).

$$
\begin{aligned}
P_{2}^{*} & =1-\int_{-\infty}^{\beta_{2}} f(\beta) d \beta=\int_{\beta_{2}}^{\infty} f(\beta) d \beta \\
& =\int_{\beta_{2}}^{\infty} \frac{1}{\sqrt{2 \pi}} \exp \left(-\frac{\beta^{2}}{2}\right) d \beta .
\end{aligned}
$$

Therefore repairing probability of 1 st repairing time can be written as Eq. (6)

$$
P_{2}=\left(1-P_{1}\right) \times P_{2}^{*}
$$

With increasing number of repairing, $P_{n}$ which means nth repairing can be formulated as Eq. (7). With a given repairing cost of $C$, total repairing cost with increasing service life can be written as Eq. (8) with simple multiplying $C$.

$$
\begin{aligned}
& P_{n}=\left(1-\sum_{k=1}^{n-1} P_{k}\right) \times P_{n}^{*} \\
& C_{\text {total }}=\sum_{k=1}^{n}\left(k C P_{k}\right)
\end{aligned}
$$

\section{Simulation of Repairing Cost Estimation Considering Probabilistic Distributions}

\subsection{Repairing Cost and Governing Deterioration}

In the section, LIFE 365 program is utilized for evaluation of chloride penetration and service life for RC structure exposed to chloride attack. The target structure is assumed to be located in sea shore with $80 \mathrm{~mm}$ cover depth. The mix 


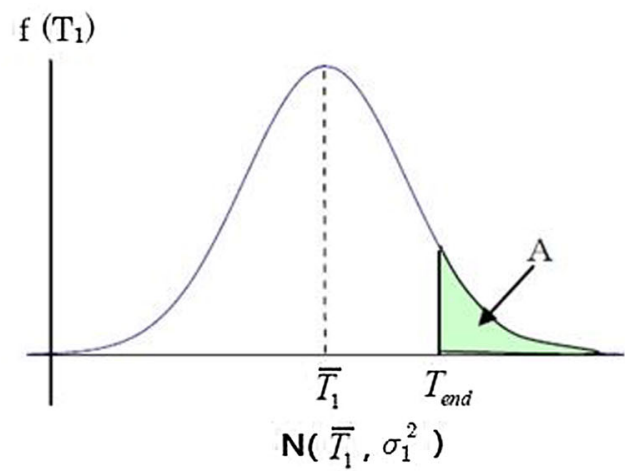

Normal distribution

$\mathrm{f}(\mathrm{T})$

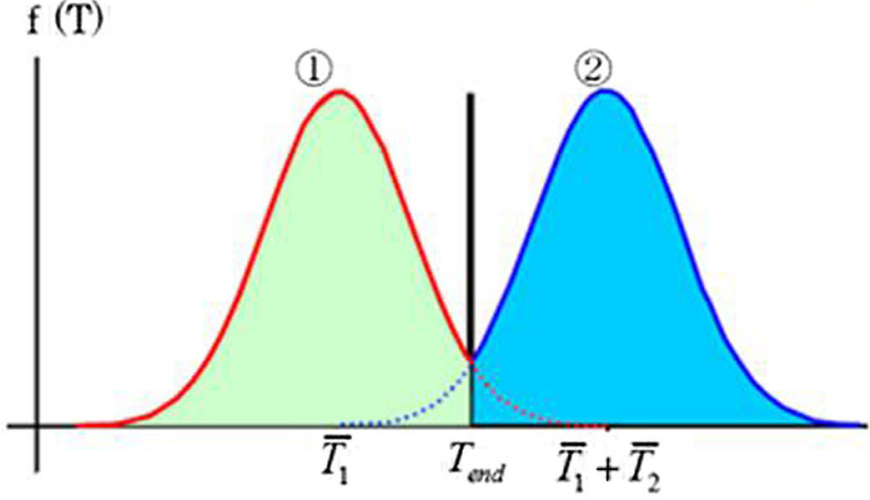

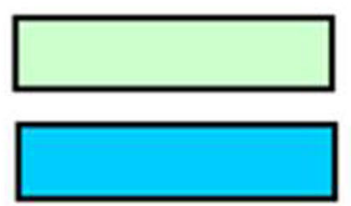

Area $C\left(1-P_{1}\right)$

Area $\mathrm{D}\left(P_{2}^{*}\right)$

Area $\mathrm{B}\left(P_{2}\right)$

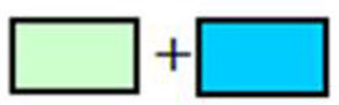

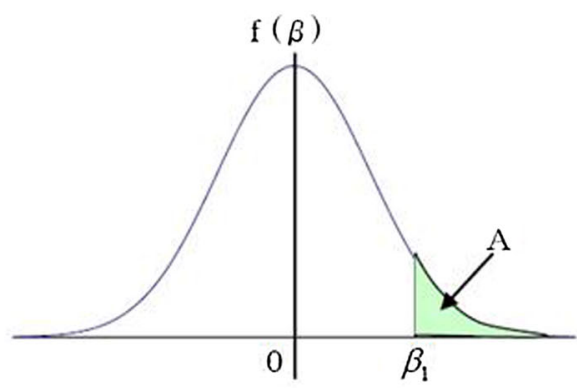

$\beta \mathrm{N}(0,1)$

Normal distribution

$$
T_{1}+T_{2} \sim N\left(\overline{T_{1}}+\overline{T_{2}}, \sigma_{1}{ }^{2}+\sigma_{2}{ }^{2}\right)
$$

Fig. 1 Concept of repair probability for the 1st repairing timing.

proportions of concrete are listed in Table 1. For comparison of repair cost with increasing service life, three representative mixtures are considered.

In order to evaluate actual intrusion of chloride penetration, time dependent diffusion behavior is considered with critical chloride threshold of $1.2 \mathrm{~kg} / \mathrm{m}^{3}$. The $1 \mathrm{st}$ repairing time can be determined when the induced chloride content exceeds $1.2 \mathrm{~kg} / \mathrm{m}^{3}$. When using repair materials, chloride penetration is significantly reduced and the residual service life increases depending on quality of repair materials and the variation of cover depth.
In the study, repair timing is calculated at $T_{1}$ assuming the concrete with the same mix proportions and $10 \mathrm{~mm}$ of additional cover depth in order to evaluate an effect of extended service life. The flowchart for evaluation of chloride penetration is summarized in Fig. 2.

\subsection{Calculation of Repairing Cost Considering} Probability Distribution of Service Life

\subsubsection{Analysis Conditions and Repair Cost}

In order to determine initial service life $\left(T_{\text {end }}\right)$ and extended service life through $\mathrm{Nth}$ repair $\left(T_{N}\right)$, analysis conditions

Table 1 Mix proportions of concrete.

\begin{tabular}{|c|c|c|c|c|c|c|c|c|}
\hline & \multirow[t]{2}{*}{$\mathrm{W} / \mathrm{B}(\%)$} & \multirow[t]{2}{*}{ S/a (\%) } & \multicolumn{5}{|c|}{ Unit weight $\left(\mathrm{kg} / \mathrm{m}^{3}\right)$} & \multirow[t]{2}{*}{ SP $(\%)$} \\
\hline & & & $\mathrm{W}$ & $\mathrm{C}$ & $\mathrm{SG}$ & $\mathrm{S}$ & $\mathrm{G}$ & \\
\hline OPC & 37 & 42.0 & 168 & 454 & 0 & 767 & 952 & 9.08 \\
\hline SG30 & 42 & 42.0 & 168 & 280 & 120 & 972 & 783 & 5.61 \\
\hline SG50 & 47 & 42.0 & 168 & 179 & 179 & 853 & 832 & 3.58 \\
\hline
\end{tabular}

$W / B$ water-binder ratio, $W$ water, $C$ Ordinary Portland Cement, $S G$ ground granulated blast furnace slag (GGBFS), $S$ sand, $G$ gravel, $S P$ super plasticizer. 


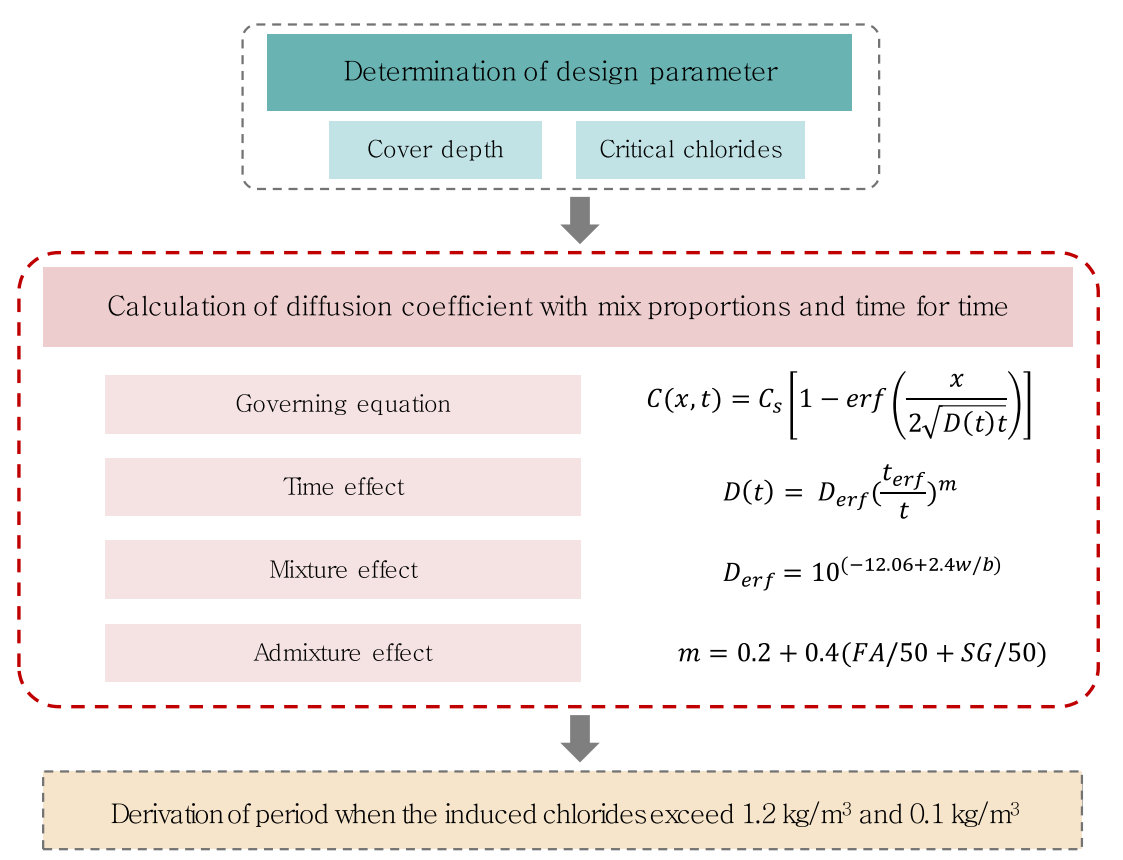

Fig. 2 Flowchart for chloride penetration and calculation.

Table 2 Analysis conditions for chlorides evaluation using LIFE 365.

\begin{tabular}{c|c}
\hline Surface chloride content & $23.5 \mathrm{~kg} / \mathrm{m}^{3}$ \\
\hline Temperature & Constant $15^{\circ} \mathrm{C}$ \\
\hline Time to build up & 10.0 years \\
\hline Cover depth & $80 \mathrm{~mm}$ \\
\hline Critical chloride content & $1.2 \mathrm{~kg} / \mathrm{m}^{3}$ \\
\hline Service life determination & $1.2 \mathrm{~kg} / \mathrm{m}^{3}$ for initial condition \\
\hline
\end{tabular}

for chloride penetration are prepared as Table 2. The results of predicted service life are summarized as Table 3 . The chloride behavior and diffusion coefficient with time are shown in Fig. 3a and b, respectively.

The evaluation using LIFE 365, it is shown that arrivals of threshold chloride contents at rebar location are 11.8 years for OPC, 18.2 years for SG30, and 24.3 years for SG50, respectively. Repairing concrete with the same mix conditions with additional $10 \mathrm{~mm}$ is assumed for more extended service life $\left(\mathrm{T}_{\mathrm{N}}\right)$ and the results are 14.1 years for OPC, 22.8 years for SG30, and 31.3 years for SG50, respectively. The required numbers of repair for 100 years are 7 times for OPC, 4 times for SG30, and 3 times for SG50 based on conventional method, which are shown in Fig. 4.

In case of SG30 and SG50, long-term service life is evaluated due to a reduced diffusion coefficient despite of higher ratios of water-binder ratios. This is because diffusion coefficient drops dramatically due to the decrease in

Table 3 Results for calculation of service life (years).

\begin{tabular}{c|c|c}
\hline Case & Repair timing (year) \\
\hline \hline \multicolumn{2}{|c|}{ Initial service life } & 11.8 \\
\hline OPC & 18.2 \\
\hline SG30 & 24.3 \\
\hline SG50 & & 14.1 \\
\hline \multicolumn{2}{|c|}{ Extended service } \\
\hline OPC & & 22.8 \\
\hline SG30 & & 31.3 \\
\hline
\end{tabular}




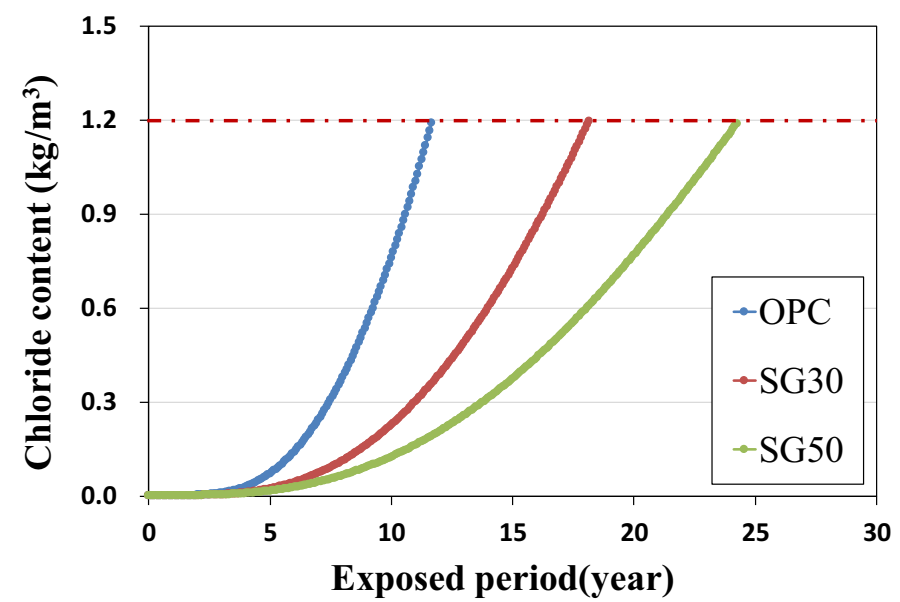

(a) Chloride content of each mix proportions at exposed period

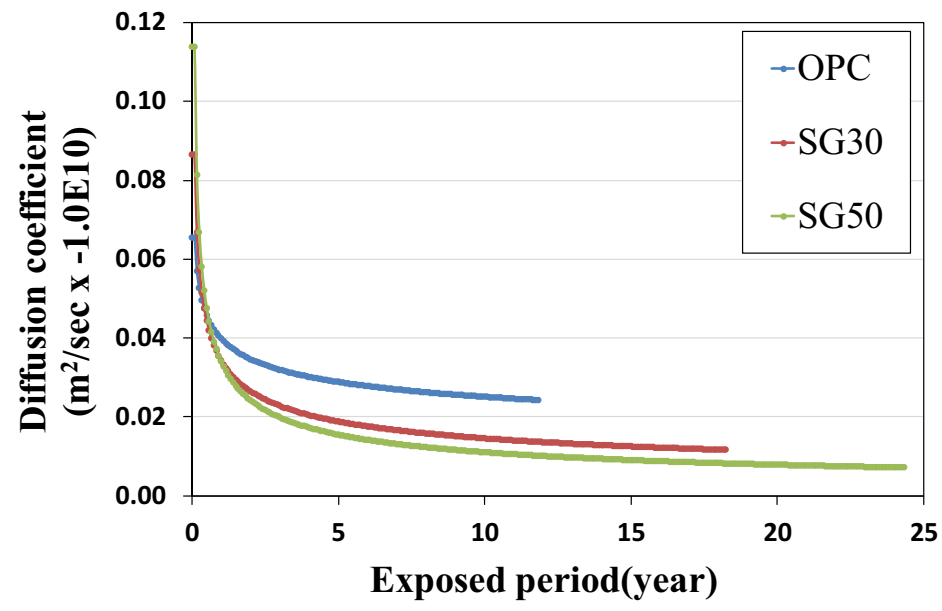

(b) Decreasing diffusion coefficient with mix conditions

Fig. 3 Calculation of chloride behavior for various mix proportions.

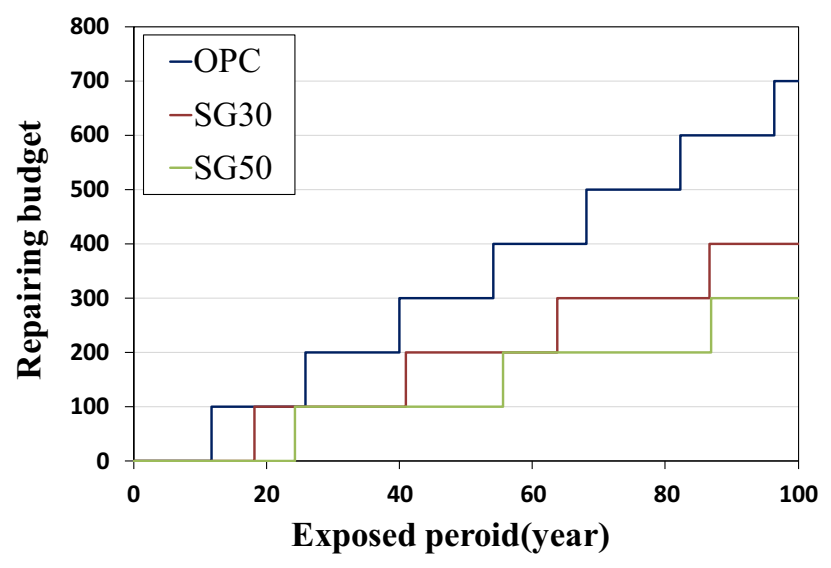

Fig. 4 Repairing number and required budget for each mix conditions.

pore structure and increase in chloride adsorption in concrete with slag, which has been reported in many literatures (Kwon 2017; Thomas and Bamforth 1999; Thomas and Bentz 2002).

\subsubsection{Changes of Probabilistic Properties}

The analysis condition for probabilistic method is assumed in Table 4 for evaluation of repair cost depending on each mix design when intended service life is determined as 100 years. The results from LIFE 365 are adopted for service life prediction.

The coefficient of variation (COV) is set as 0.2 for $T_{1}$ and 0.25 for $T_{2}$. Figure 5 shows a varying repair cost depending on each mix design when using probabilistic model with the conditions mentioned above. When calculating repair cost by probabilistic model, repair cost can be obtained at arbitrary service life not at repair timing unlike conventional deterministic model.

When calculating repair frequency for satisfying 100 years of service life from probabilistic model, the required repair frequency is 6.71 for OPC, 4.09 for SG30, and 2.95 for SG50.

When using probabilistic model, it is possible to calculate minimum repair frequency by adjusting intended service life, and this enables optimum repair cost efficiently. For example, when probabilistic model provides $12-18$ or 26-33 years for OPC, and 19-27 or 42-52 years for SG30, and 24-36 or 56-68 years SG50, repair cost can be saved by more than 1 time compared to the results from deterministic model. 
Table 4 Analysis conditions for repairing budget.

\begin{tabular}{|c|c|c|c|c|}
\hline \multicolumn{2}{|c|}{ Case } & $\mathrm{OPC}$ & SG30 & SG50 \\
\hline \multicolumn{2}{|c|}{ Intended service life (years) } & 100 & 100 & 100 \\
\hline \multicolumn{2}{|c|}{ 1st repairing period (years) } & 11.8 & 18.2 & 24.3 \\
\hline \multicolumn{2}{|c|}{ Repairing period (years) over 1st time } & 14.1 & 22.8 & 31.3 \\
\hline $\mathrm{COV}$ & 1st time & 0.2 & 0.2 & 0.2 \\
\hline
\end{tabular}

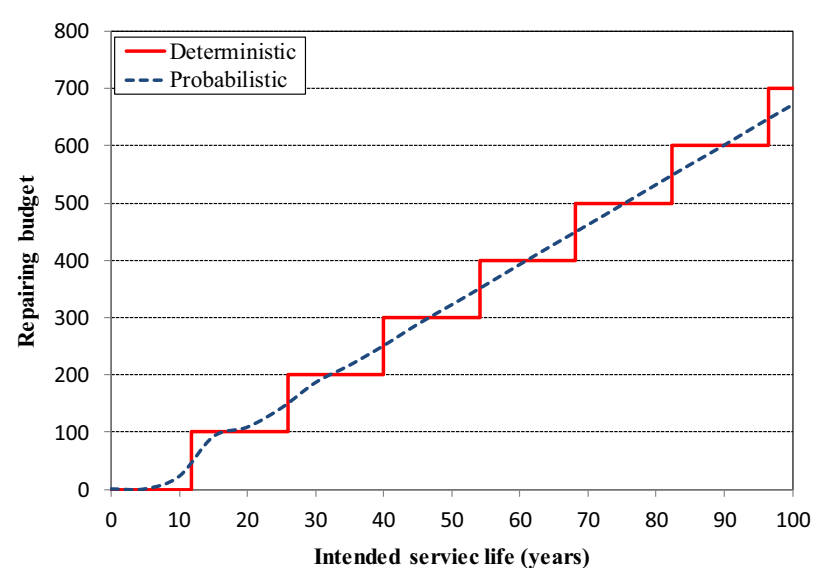

(a) Repairing cost for OPC

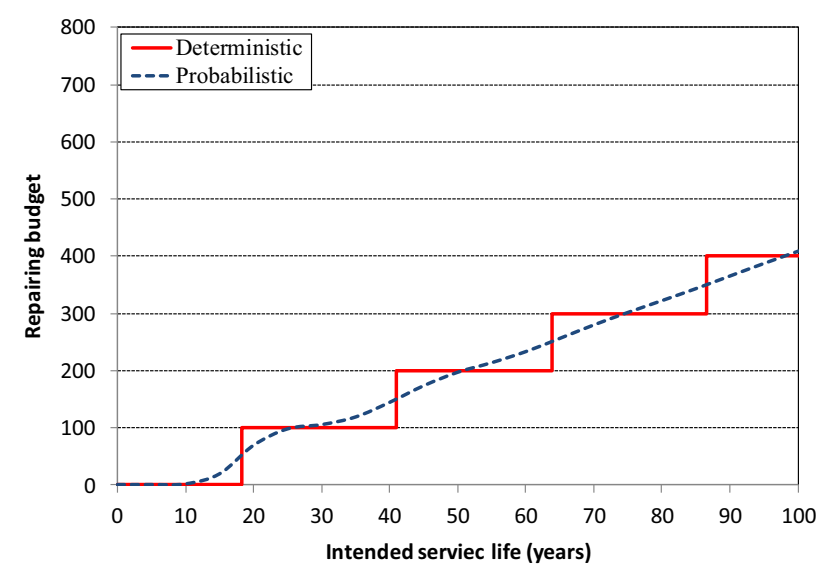

(b) Repairing cost for SG30

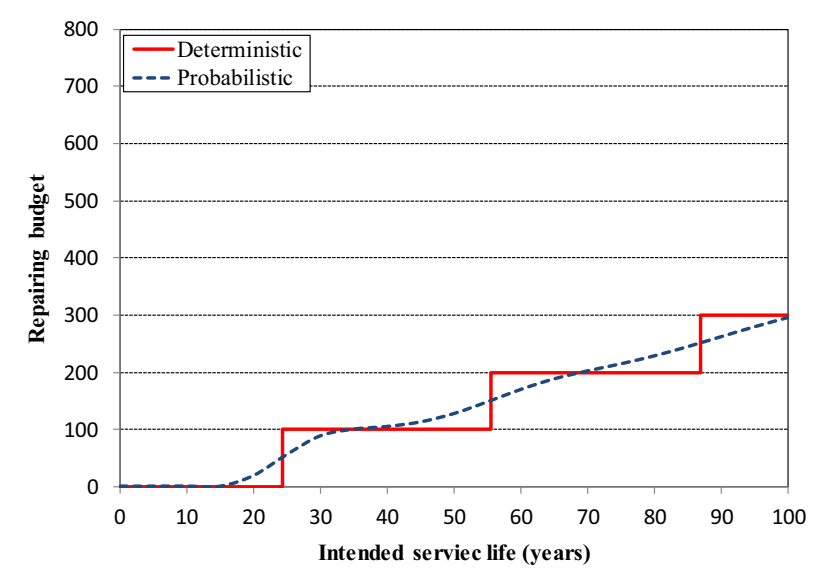

(c) Repairing cost for SG50

Fig. 5 Comparison of repairing budget between deterministic and probabilistic model.

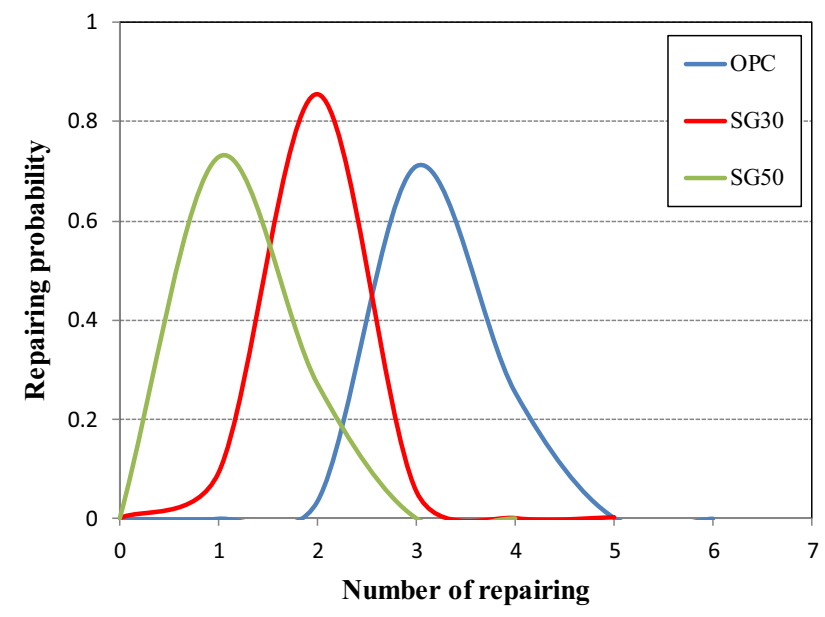

(a) Repairing probability

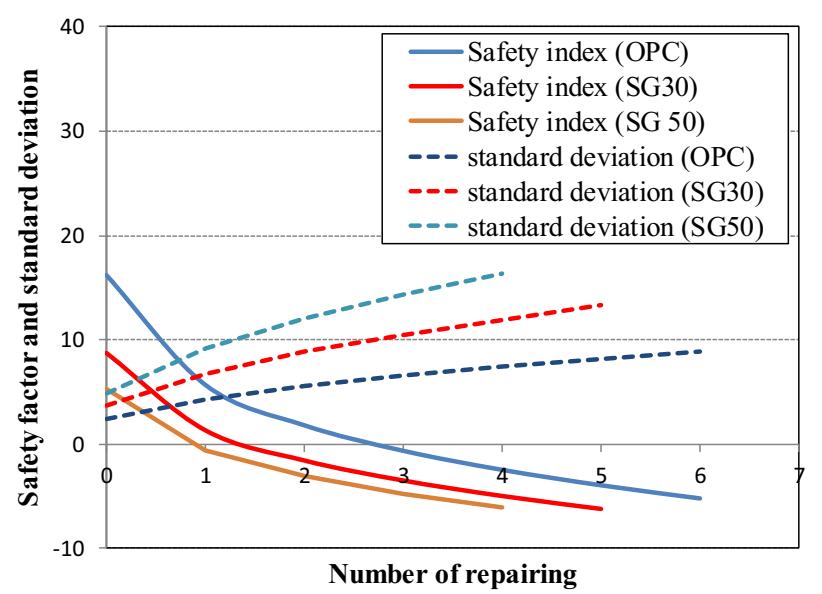

(b) Safety index and standard deviations

Fig. 6 Random variable properties of OPC, SG30 and SG50 for $T_{\text {end }}$ of 50 years.

In the results from probabilistic model, mean value of repair frequency, safety index (normalized parameter) at each repair timing, and the increasing standard deviation with repeated repair can be calculated with changes in repair numbers.

Figure 6 shows repairing probability and safety index according to the increase of replacement ratio of slag at 50 years of service year. The probability of repair frequency is average 3.4 for OPC, 1.9 for SG30, and 0.9 for SG50. And higher standard deviation is shown due to the increased difference of $T_{1}$ and $T_{2}$ caused by higher replacement ratio of slag, which leads to lower safety index. 


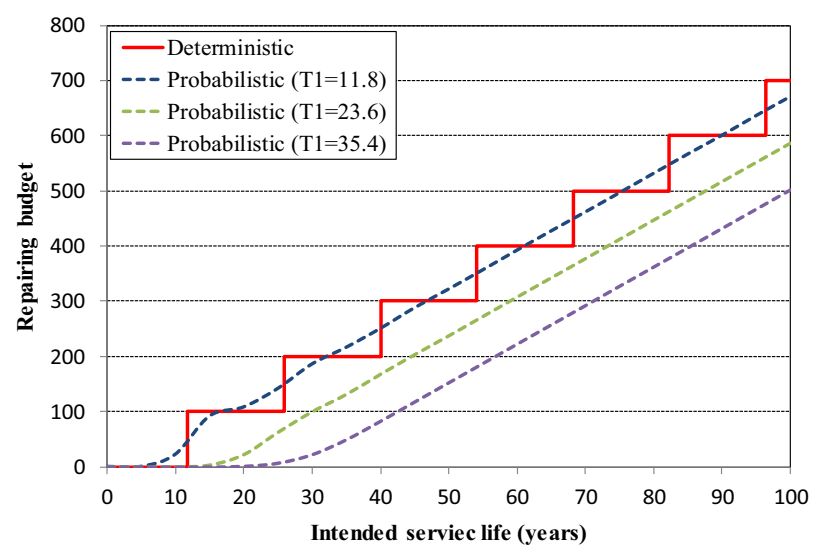

(a) Repairing cost for OPC

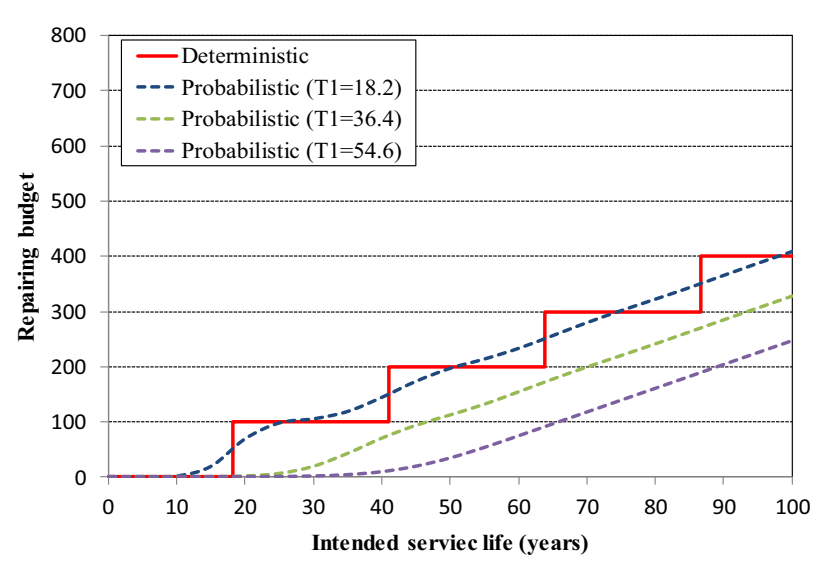

(b) Repairing cost for SG30

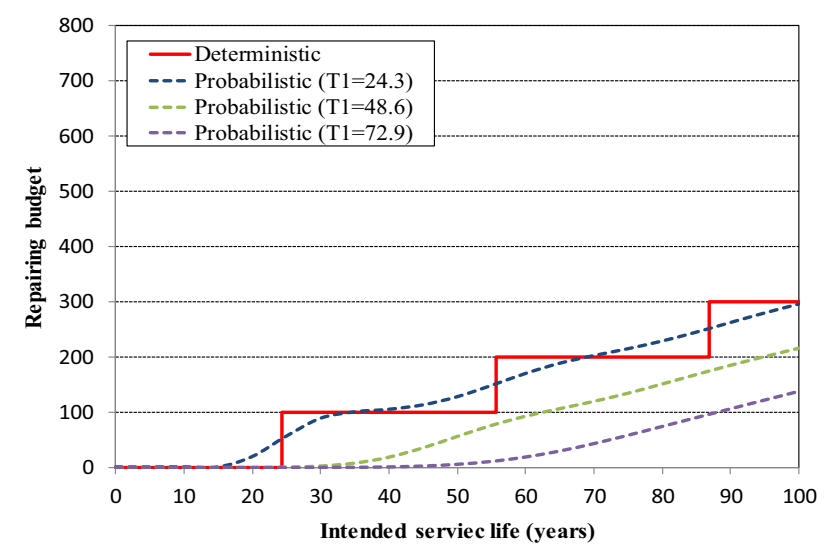

(c) Repairing cost for SG50

Fig. 7 Simulation results for extended maintenance free period.

\section{Effects of Design Parameter on Repair Cost}

\subsection{Effects of Extension Initial Service Life}

In order to evaluate an effect of intended service life on repair cost, cost simulation is performed with increasing maintenance-free period $\left(T_{1}\right)$ to three times.

As shown in Fig. 7, 5.87 repair frequency is required when $T_{1}$ increases to 2 times, and 5.01 is required to 3 times increase of $T_{1}$, while OPC mix condition with $T_{1}$ needs 6.71 repair frequency for 100 years of service life. In the case of

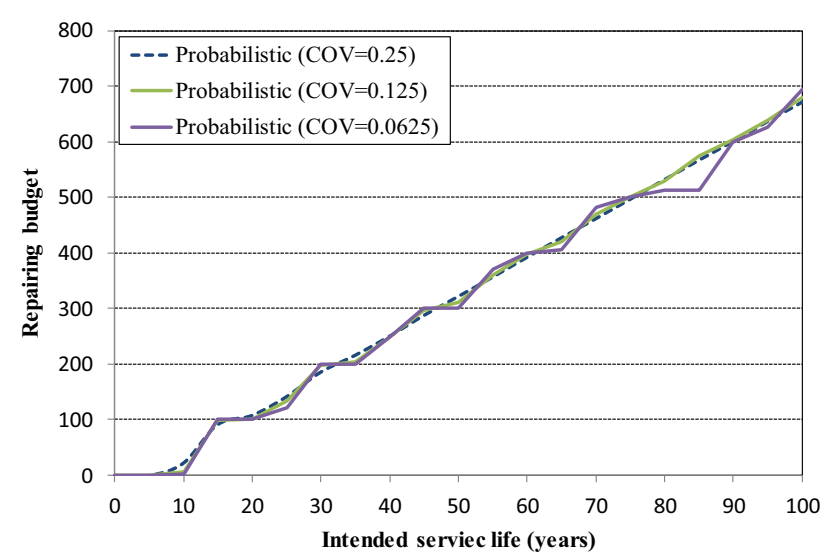

(a) Repairing cost for OPC

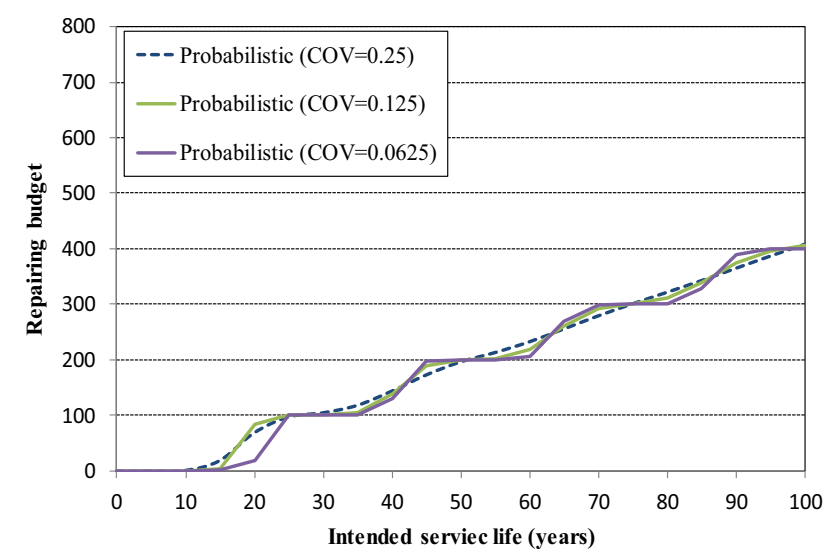

(b) Repairing cost for SG30

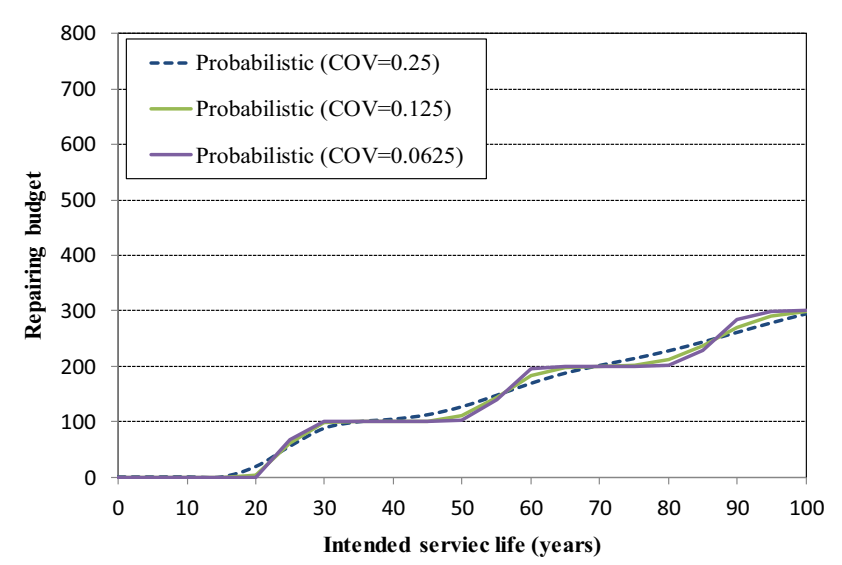

(c) Repairing cost for SG50

Fig. 8 Simulation results for varying COV.

SG30, 3.28 and 2.47 repair frequencies are required for 2 and 3 times increases in $T_{1}$, respectively while 4.09 repair frequency is required in the normal condition. For SG50 case, 2.15 and 1.36 repair frequencies are required, respectively while basic condition shows 2.95 frequencies for 100 years.

The extension of maintenance free period is evaluated to be very effective to cost-benefit repair planning and the effect is still dominant in the concrete mixture contain slag (SG30 and SG50). 


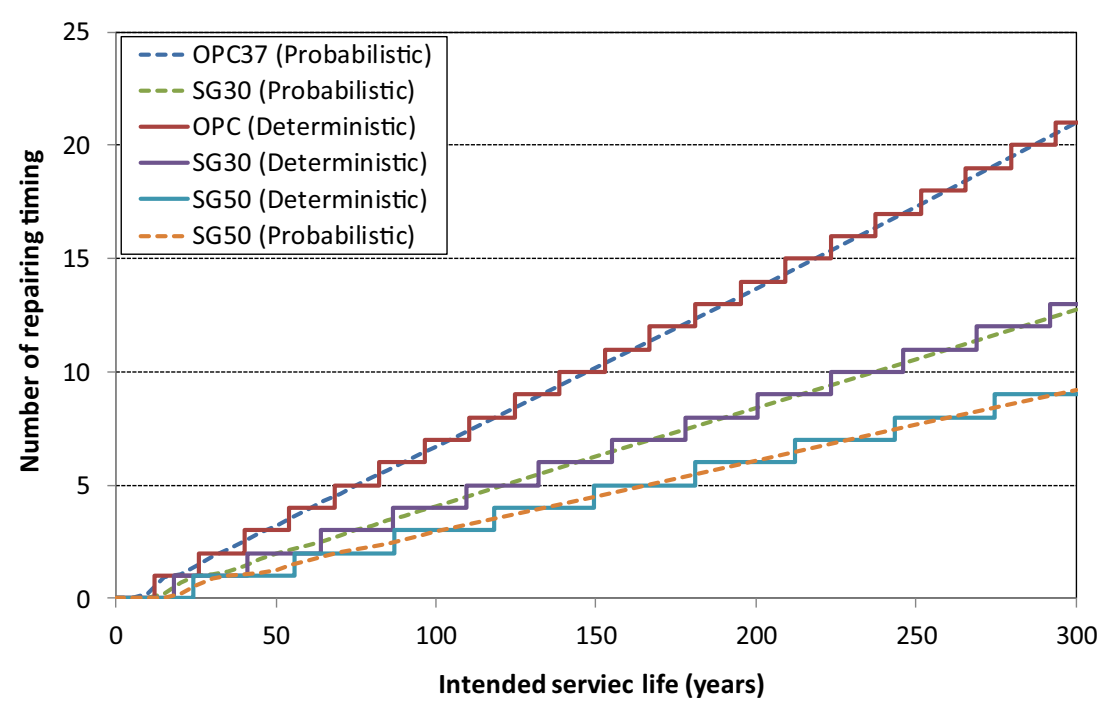

Fig. 9 Numbers of repairing timing with extension of intended service life.

\subsection{Effects of COV of Repair Quality}

In the Sect 4.2, an effect of COV which can represent a repair quality on cost is evaluated. The probability parameters (mean value and standard deviation) vary with changes in constructability and quality of materials. Figure 8 shows simulation results for varying COV. The initial simulation conditions for $\mathrm{COV}$ are 0.20 and 0.25 for $T_{1}$ and $T_{2}$, respectively. The simulation for cost is performed with decreasing $\mathrm{COV}$ to $25 \%$.

From the simulation, it is shown that 6.71 repair frequency is required for initial condition of OPC for 100 years. With decreasing COV to 50 and $25 \%$, the repair frequencies are evaluated to be 6.54 and 6.37 , respectively. In the case of SG30, 4.09, 4.05, and 4.00 repair frequency are evaluated while $2.95,2.86$, and 2.67 times are evaluated in the case of SG50.

Repair frequency has insignificant changes with decreasing $\mathrm{COV}$ but the trend of cost function changes to similar trend from deterministic method since the minimized COV yields deterministic results. It is desirable to consider a reasonable $\mathrm{COV}$ through evaluation of material quality and construction level.

\subsection{Effects of Increasing Service Life}

An extension of intended service life requires more repeated repair frequencies and cost for maintenance. Repair frequency and repair cost with each mix design is evaluation with increasing intended service life to 300 years.

Figure 9 represents repeated repair frequencies and cost of OPC, SG30 and SG50 by setting 300 years of intended service life. The section where the repair cost derived by deterministic and probabilistic approaches are identically calculated is $20 \%$ for OPC, $30 \%$ for SG30, and $40 \%$ for SG50. Therefore, repair frequencies are regarded to be decreased by setting intended service life considering the result mentioned above.

\section{Conclusions}

In the work, the number of repairing and the related cost are evaluated through deterministic and probabilistic approaches for RC column exposed to chloride spraying condition with three different mix proportions. The conclusions on the work are as follows.

(1) Through analysis of chloride behavior, maintenance free periods for OPC, SG30, and SG50 are evaluated to $11.8,18.2$, and 24.3 years, respectively. The extended service lives with same mix proportions and additional $10.0 \mathrm{~mm}$ of cover depth are $14.1,22.8$, and 31.3 years, respectively.

(2) With three mix proportions with the same exposure condition, repair frequency is evaluated based on deterministic and probabilistic manner. In the deterministic manner, 7, 4, and 3 repair times come while $6.71,4.09$, and 2.95 times of repairing are evaluated since the results from probabilistic method yields a continuous cost function with increasing service life. Through simple modification of intended service life and extension of service life with repair material, effective maintenance strategy can be obtained with probabilistic method.

(3) With increasing $\mathrm{T}_{1}$ to 2 times, 5.87 times for OPC, 3.28 for SG30, and 2.15 times for SG50 are evaluated for repairing frequency for 100 years of intended service life. If it increases to 3 times, 5.01, 2.47, and 1.36 times of repairing are evaluated for OPC, SG30, and SG50, respectively, which shows that mix conditions containing slag and extension of maintenance free period $\left(\mathrm{T}_{1}\right)$ are very effective to saving repairing cost for entire service life.

With changes in COV which can reflect variation of repair material and quality, repairing cost varies insignificantly and the results from decreasing COV go to those from deterministic method. It verifies that 
the control of COV has a little effect on total repairing cost but it is important to the maintenance plan near to each repairing stage.

\section{Acknowledgements}

This research was supported by Basic Science Research Program through the National Research Foundation (NRF) of Korea funded by the Ministry of Science, ICT and Future Planning (No. 2015R1A5A1037548).

\section{Open Access}

This article is distributed under the terms of the Creative Commons Attribution 4.0 International License (http:// creativecommons.org/licenses/by/4.0/), which permits un restricted use, distribution, and reproduction in any medium, provided you give appropriate credit to the original author(s) and the source, provide a link to the Creative Commons license, and indicate if changes were made.

\section{References}

Al-Amoudi, O. S. B., Al-Kutti, W. A., Ahmad, S., \& Maslehuddin, M. (2009). Correlation between compressive strength and certain durability indices of plain and blended cement concretes. Cement and Concrete Composites, 31(9), 672-676.

Alonso, C., Castellote, M., \& Andrade, C. (2002). Chloride threshold dependence of pitting potential of reinforcements. Electrochemica Acta, 47(21), 3469-3481.

American Concrete Institute, ACI. (2011). Building code requirements for structural concrete and commentary. ACI 318-11. Detroit, MI: American Concrete Institute (ACI).

Barringer, H. P., \& Weber, D. P. (1997). Life cycle cost and reliability for process equipment. In: 8th Annual energy week conference and exhibition (pp 1-22). Houston, TX: American Petroleum Institute.

Bian, J., Sun, X., Wang, M., Zheng, H., \& Xing, H. (2014). Probabilistic analysis of life cycle cost for power transformer. Journal of Power and Energy Engineering, 2(4), 489-494.

Broomfield, J. P. (1997). Corrosion of steel in concrete: Understanding, investigation and repair (pp. 1-15). London: E\&FN.

Chan, A., Keoleian, G., \& Gabler, E. (2008). Evaluation of lifecycle cost analysis practices used by the Michigan Department of Transportation. Journal of Transportation Engineering, 134(6), 236-245.
European Committee for Standardization (Comité Européen de Normalisation, CEN). (2000). Eurocode 1: Basis of design and actions on structures. EN-1991. Brussels: European Committee for Standardization (Comité Européen de Normalisation, $\mathrm{CEN}$ ).

Flintsch, G. W., \& Chen, C. (2004). Soft computing applications in infrastructure management. Journal of Infrastructure Systems, 10(4), 157-166.

Japan Society of Civil Engineering, JSCE. (2007). Standard specification for concrete structures-Materials and construction. JSCE-Guidelines for Concrete 16. Tokyo: Japan Society of Civil Engineering (JSCE).

Kwon, S.-J. (2017). Current trends of durability design and government support in South Korea: Chloride attack. Sustainability. https://doi.org/10.3390/su9030417.

Martinez, L. H. (2001). A neuro-fuzzy decision support system for risk analysis of revenue-dependent infrastructure projects. PhD Dissertation, Purdue University, Department of Civil Engineering, West Lafayette.

Mulubrhan, F., Mokhtar, A. A., \& Muhammad, M. (2014). Integrating reliability analysis in life cycle cost estimation of heat exchanger and pump. Advanced Materials Research, 903, 408-413.

Nasir, M., Chong, H. Y., \& Osman, S. (2015). Probabilistic life cycle cost model for repairable system. IOP Conference Series: Materials Science and Engineering, 78(2015), 1-8.

Rahman, S., \& Vanier, D. J. (2004). Life cycle cost analysis as a decision support tool for managing municipal infrastructure. In: Proceedings of the CIB triennial, CIB 2005 triennial congress, Toronto, Canada (pp 1-11).

Salem, O., Abourizk, S., \& Ariaratnam, S. (2003). Risk-based life-cycle costing of infrastructure rehabilitation and construction alternatives. Journal of Infrastructure Systems, 9(1), 6-15.

Song, H.-W., Pack, S.-W., Lee, C.-H., \& Kwon, S.-J. (2006). Service life prediction of concrete structures under marine environment considering coupled deterioration. Journal of Restoration of Buildings Monuments, 12(4), 265-284.

Swei, O., Gregory, J., \& Kricahin, R. (2013). Probabilistic characterization of uncertain inputs in the life-cycle cost analysis of pavements. Transportation Research Record. https://doi.org/10.3141/2366-09.

Thomas, M. D. A., \& Bamforth, P. B. (1999). Modeling chloride diffusion in concrete: Effect of fly ash and slag. $\mathrm{Ce}$ ment and Concrete Research, 29(4), 487-495.

Thomas, M. D. A., \& Bentz, E. C. (2002). Life- $365^{T M}$ Service Life Prediction Model ${ }^{T M}$ and computer program for predicting the service life and life-cycle costs of reinforced concrete exposed to chlorides (pp 2-28). SFA.

TOTAL-LCC (2010). Technical manual, ver.1.1. 